\title{
HYPOTHESIS OF TUMBLEWEED-LIKE DISPERSAL OF DROSERA SEEDS
}

RoBERT GIBSON • Cardiff Heights • NSW 2285 • Australia • robert.gibson@environment.nsw.gov.au

Erect-growing tuberous sundews of Drosera subgenus Ergaleium section Ergaleium produce seeds of diverse size and shape (Lowrie 2013). Seeds produced by such species as $D$. andersoniana, D. macrantha, and D. pallida are large and winged, and fit the classic model of those dispersed by the wind (Lowrie 2013: Vol. 2, p. 508), i.e. pterometeorochory. However, many species in this section produce small, round seeds (e.g. D. gigantea, D. salina, and D. yilgarnensis) that appears better suited to dispersal by gravity or water than by the wind. So how do you explain how these taxa spread across the landscape when some of their seed appear to be poor candidates for long-distance dispersal?

The situation is trickier when you consider that most tuberous Drosera are self-incompatible; that is, they need genetically compatible plants from different seeds to grow and flower in close proximity to enable cross-pollination. The long-distance dispersal of large, winged Drosera seed comes with low likelihood that seeds will land close enough together for any resulting plants to cross-pollinate. And yet, large and fecund populations of these sundews occur, often separated by hostile territory.

A characteristic feature of Drosera flowers is that the floral parts are retained after anthesis (Fleischmann et al. 2018). The petals wither and often cover the apex of the fruit. The sepals also enclose the fruit. This results in small gaps through which individual seeds may fall. However, seed is often retained in the dry fruit.

During fieldwork in south western Australia in October 2019, I made observations that revealed a way in which these sundews may disperse seed across the landscape, and to do so in a way that better guarantees resulting plants will form viable populations.

Conditions during recent fieldwork were warmer and drier than usual, and so many sites I visited had dried out and plants were dormant. The dead remains of tuberous Drosera dry black or dark brown and were readily visible amongst the other herbs. Over time they detach from the ground. However, the upper parts of many of the climbing species (such as D. macrantha) were still attached to surrounding vegetation. Importantly, many of the plants had seed in their fruit.

At Lake Hurlstone, near Hyden, most dead plants of D. zigzagia stood where they had grown. But many had been detached and had been blown into small piles against barriers (Fig. 1). This species has elongate seeds that is likely to be blown some distance on the wind. But it grows on the edge of salt lakes - an environment hostile to seeds that land there. The same applies to D. salina, from the same environment and region, but it has small round seeds that have very low chance of long-distance wind dispersal. Instead, I propose here, that long-distance dispersal of these species may also be facilitated by the transport of detached plant parts, with seed, by the wind - in a manner more akin to some grasses (such as Panicum effusum) that may be air-born for part of the journey than as a true tumbleweed (Salsola species: Chenopodiaceae), i.e. chamaechory. This has the added advantage of increasing the chance of groups of compatible plants getting established in close proximity. Given most plants would be closely-related, this would be a driver for potential speciation.

During fieldwork I also observed that even those sundews with seeds classically adapted for wind pollination often grew as isolated groups. This suggests that a proportion of these seed stays close to the parent plant. This offers the same advantage of a higher chance of seed set. It also suggests that long-distance wind-dispersal of plant parts with seeds may be a rarer event than for smaller taxa in exposed situations. 


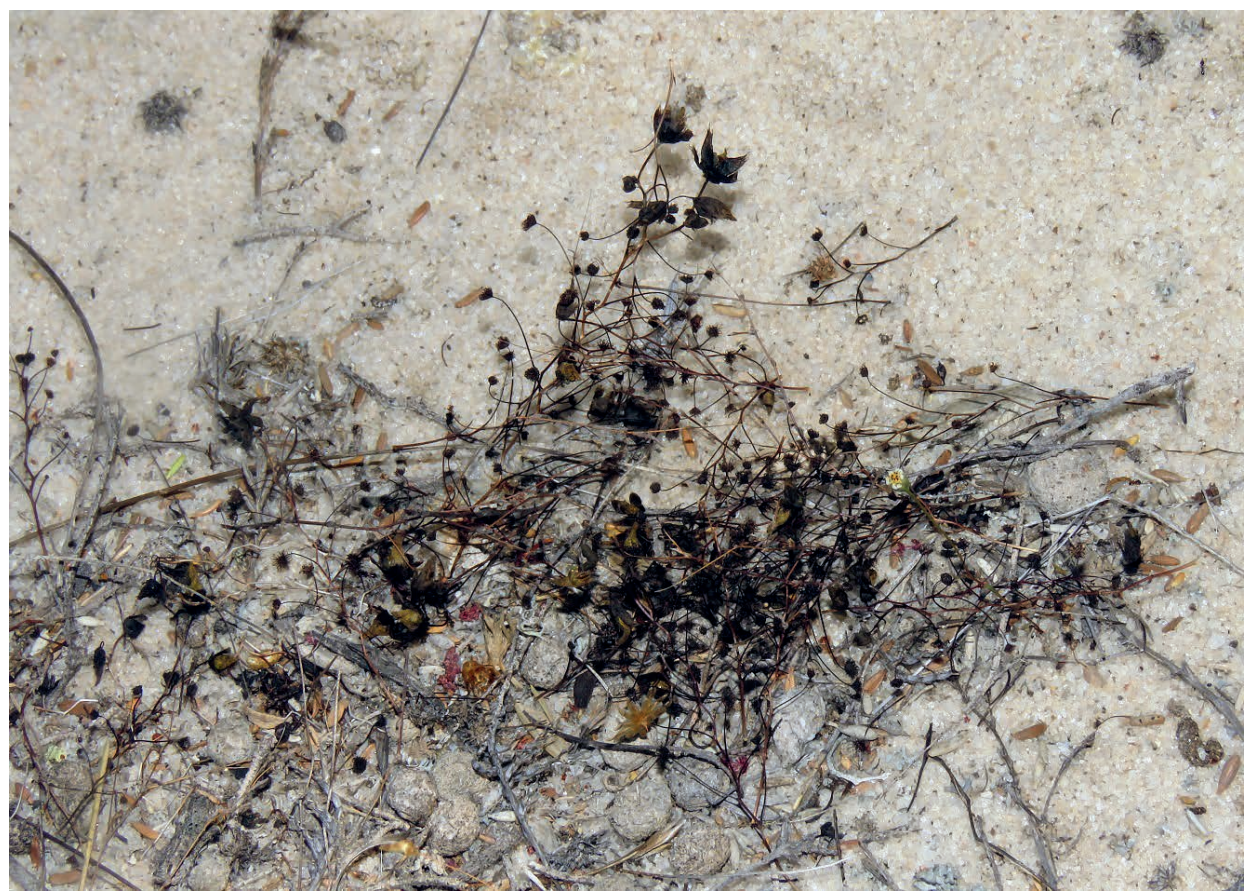

Figure 1: Drosera zigzagia near Hyden. Dead plants with seed have been detached, moved, and formed small piles against barriers, and appear to be an example of chamaechory.

This hypothesis is yet another way (Gibson 2015) that seeds of sundews may be spreading around the landscape. It suggests that the seeds of some taxa have multiple ways of traveling over a landscape, and to increase the chance of founding new populations.

Acknowledgement: I thank Allen Lowrie for discussions on the subject of Drosera seed dispersal that have kept me thinking about this interesting topic.

\section{References}

Fleischmann, A., Cross, A.T., Gibson, R., Gonella, P.M., and Dixon, K.W. 2018. Chapter 4: Systematics and evolution of Droseraceae. In: A.E. Ellison and L. Adamec (Eds.) Carnivorous Plants: Physiology, Ecology, and Evolution. Oxford University Press, Oxford, pp. 45-57.

Gibson, R. 2015. Hypothesis of mucilage-assisted dispersal of Drosera seeds. Carnivorous Plant Newsletter 44: 195-196.

Lowrie, A. 2013. Carnivorous Plants of Australia: Magnum Opus. Redfern Natural History Productions, Poole. 